\title{
Probing current, voltage and metal transfer characteristics in pulsed arc and in conventional and a novel low energy input short arc GMAW*
}

\author{
by Sven-F Goecke**, Arshad Alam Syed***, Michael Ebert-Spiegel**** and Amitava De*****
}

\begin{abstract}
An accurate control over the rate of heat input and material deposition is essential in gas metal arc welding for its greater use in joining of sheet metals. Although pulsed current gas metal arc welding facilitates excellent control over the rate of material deposition, greater rate of heat input due to high peak pulses remains critical. Gas metal arc welding with conventional short-circuiting mode of metal transfer provides a significant reduction in the rate of heat input while an uninterrupted and spatter-free material deposition is too difficult to achieve. A novel low energy input short-circuiting gas metal arc welding is proposed here that facilitates short-circuiting mode of metal transfer with a very low power detachment phase. Here we present an investigation on the current, voltage and consequent metal transfer sequences in pulsed current, and the conventional and the novel low energy input short-circuiting gas metal arc welding processes of high strength automotive steel sheets. It is realized that the low energy input short-circuiting process could provide uninterrupted and nearly spatter-free metal transfer at significantly reduced electrical power in comparison to both pulsed current and conventional short-circuiting gas metal arc welding. The low energy input short-circuiting process could also facilitate fairly small angular distortion of weld joints.
\end{abstract}

Key Words: GMAW, Metal transfer, Pulsed arc, Conventional and low energy input short arc, On-line monitoring, High speed images

\section{Introduction}

Gas metal arc welding (GMAW) process is widely used in automotive and other associated industries for joining of a variety of parts in thin metallic sheets. Although pulsed current GMAW or commonly referred to GMAW-P allows excellent control over the rate of heat input and of metal transfer, high current peaks and consequent heat input that may result in burn through or significant thermal damage have remained as a concern ${ }^{1-5)}$. The conventional short-circuiting GMAW process, which is also referred to as SCAW, allows significant reduction in the rate of heat input as the arc is extinct during the short-circuiting mode of metal transfer. However, violent re-ignition of the welding arc at the end of metal transfer and resulting uncontrollable spatter have traditionally restricted greater use of SCAW process in joining of thin sheets ${ }^{6-8}$. The present work reports the recent development of an advanced low energy input short-circuiting GMAW process that facilitates the arc re-ignition only after a controlled drop-down of the short-circuiting current leading to a substantial reduction in the heat input during the most sensitive short-circuiting detachment phase ${ }^{9-12)}$. Although the low energy input short-circuiting process provides a significant improvement over the conventional SCAW process, lack of physical understanding of the nature of the current and voltage transients and their interrelation as well as of the corresponding sequences of material transfer has inhibited the

\footnotetext{
*Received: 2012.11.29

*** Professor, University of Applied Science, Brandenburg an der Havel, Germany.

${ }^{* * *}$ Graduate student, Mechanical Engineering,Indian Institute of Technology Bombay, India.

${ }^{* * * *}$ Graduate student, University of Applied Science, Brandenburg an der Havel, Germany.

${ }^{* * * * *}$ Professor, Mechanical Engineering,Indian Institute of Technology Bombay, India.
}

greater use of the low heat energy input SCAW process ${ }^{9-12)}$.

An integrated effort to study the nature and magnitude of current and voltage transients, and simultaneous events of metal transfer has been rare both in GMAW-P and SCAW processes. Obviously, studies in this direction have remained challenging in GMAW process due to radiant welding arc and high peak temperature ${ }^{1-4)}$. Although visual imaging sensor, infrared camera, and radiographic sensing methods are used to study real-time characteristics of GMAW process, these sensors often limit the flexibility of the process and are less reliable ${ }^{13)}$. Acoustic signals are used to relate the variations in the recorded sound waves with different phases or types of welding arc and consequent mode of metal transfers while such indirect measurement technique remains cumbersome and requires extensive calibration ${ }^{14)}$. Zhang et al ${ }^{12)}$ used high speed images to study the influence of wire feed speed on the metal transfer characteristics in GMAW process ${ }^{15)}$.

We present here an experimental study towards simultaneous assessment of current and voltage transients as well as of the events of metal transfer in GMAW-P, conventional SCAW and in the recently developed low energy input SCAW processes using a synchronized, very high-speed data acquisition and image processing system. The recorded current and voltage waveforms are analysed further to evaluate the relative magnitudes of time-averaged current, voltage and power in all these three process for a given wire feed rate during butt welding of $1.6 \mathrm{~mm}$ thick high strength automotive steels.

\section{Experimental procedure}

An inverter controlled power source (EWM alpha Q 551) is 
used to prepare all the weld samples in square-butt joint configuration in a flat position using pulsed current, conventional SCAW and the recently developed low energy input SCAW variants of GMAW at a wire feed rate of $2.5 \mathrm{~m} / \mathrm{min}$ and welding speed of $15 \mathrm{~mm} / \mathrm{s}$. Table 1 depicts the chemical composition of the workpiece, which refers to typical thermo-mechanically treated hot-rolled steel with the presence of ferrite, bainite and retained austenite phases, and the electrode wire (AWS A5.18, ER70S-6, $1.2 \mathrm{~mm})$. A shielding gas mixture of $\mathrm{Ar}(82 \%)$ and $\mathrm{CO}_{2}$ $(18 \%)$ is used at a constant flow rate of $14 \mathrm{l} / \mathrm{min}$.

Table 1 Chemical compositions (maxm. values in wt \%)

\begin{tabular}{c|ccccccc}
\hline Element & $\mathrm{C}$ & $\mathrm{Mn}$ & $\mathrm{Si}$ & $\mathrm{S}$ & $\mathrm{P}$ & \\
\cline { 1 - 6 } Workpiece & 0.12 & 2.20 & 0.80 & 0.015 & 0.040 & \\
\cline { 2 - 7 }$(\mathrm{CP}-\mathrm{W} 800)$ & $\mathrm{V}$ & $\mathrm{Al}$ & $\mathrm{B}$ & $\mathrm{Cr}+\mathrm{Mo}$ & $\mathrm{Nb}+\mathrm{Ti}$ \\
& 0.20 & 1.20 & 0.005 & 1.00 & 0.15 \\
\hline Electrode & $\mathrm{C}$ & $\mathrm{Mn}$ & $\mathrm{Si}$ & $\mathrm{S}$ & $\mathrm{P}$ & $\mathrm{Cu}$ \\
(ER70S6) & 0.08 & 1.20 & 0.68 & 0.012 & 0.012 & 0.02 \\
\hline
\end{tabular}

A pc-interfaced data acquisition system (Dewetron 5000) is used to monitor real-time monitoring of current and voltage transients at a sampling rate of $1 \mathrm{MHz}$. A closed loop Hall effect based current sensor (LEM) is used to monitor the welding current while the arc voltage is measured across the contact tip of the welding torch and the work table. The corresponding events in metal transfer are visualized using a high-speed camera (Photron Fastcam SA-1) at a rate of 54000 frames per second in dualslope-shutter mode in order to avoid the brightness of the arc.

\section{Result and discussion}

Figure 1 shows the measured current and voltage transients, and the sequentially captured images of the formation, growth and detachment of a droplet from the electrode tip through a typical current cycle in GMAW-P. Although the recordings were made for a longer welding durations, the current and voltage transients are shown only for a short duration (between zero to $0.06 \mathrm{~s}$ ) for clarity. Two vertical downward black arrows indicate the presumed duration of each current cycle consisting of both pulse-on and -off times. The position of the captured images is indicated on a specific current cycle with green coloured numbers ( 1 to 8$)$. The onset of current cycle is characterized with a small arc (image 1) followed by a rapid rise to the peak pulse $[400( \pm 5)$ A] and consequent radiant arc (images 2 to 4 ) as well as growth of the molten electrode tip. The pinching and resulting necking of the drop at the electrode tip are possibly initiated as the current pulse begins to drop (image 4) and completed with a droplet submitted to the melt pool (images 5 to 7 ). The current pulse falls through a characteristic shoulder region [at $140( \pm 5)$ A] towards the end of the pulse duration (images 6 and 7, and corresponding locations on the current cycle) to facilitate the transfer of a droplet of finite volume via the pinching effect at a relatively higher current ${ }^{13)}$. While the base current remains at $25( \pm 2) \mathrm{A}$, the peak and the base current durations are measured respectively as $5( \pm 2) \mathrm{ms}$ and $10( \pm 2)$. The values within the parenthesis indicate the variability in the measured values. Figure 1 also shows the corresponding measured voltage with initial value of $16( \pm 2) \mathrm{V}$ followed by a rapid increase to $30( \pm 2) \mathrm{V}$ consequent to the peak current. The voltage is further reduced to form a shoulder with a magnitude of $24( \pm 2) \mathrm{V}$ followed by a substantial decrease to 16 $( \pm 2) \mathrm{V}$ consequent to the base current period till the next cycle begins. The nature of the current and the voltage transients, and the corresponding trend in the formation and detachment of droplets remain repetitive through all the current cycles.

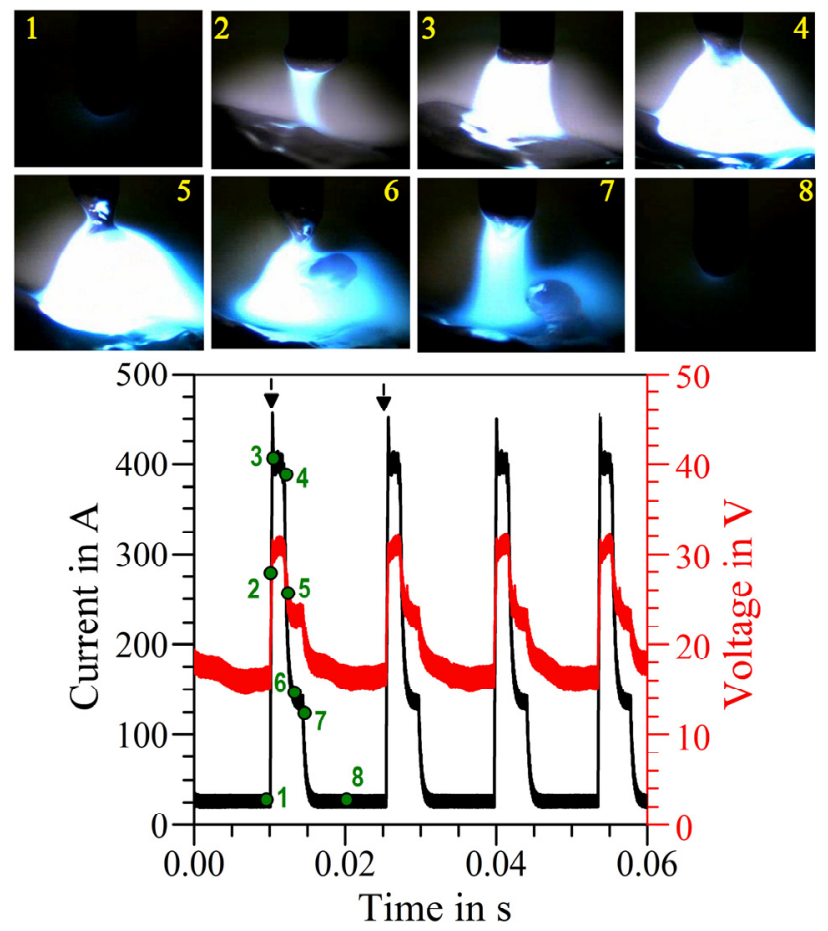

Fig. 1 Real-time current and voltage transients, and consequent sequence of metal transfer in GMAW-P at a wire feed rate of $2.5 \mathrm{~m} / \mathrm{min}$. and welding speed of $15 \mathrm{~mm} / \mathrm{s}$.

Figure 2 shows the measured current and voltage transients, and the corresponding stages of material transfer in the conventional SCAW process. The current and voltage transients are shown for a short time period of $0.14 \mathrm{~s}$ to $0.20 \mathrm{~s}$ for clarity. The typical short-circuiting and the arcing periods are indicated by two sets of vertically downward arrows in Fig. 2. It is noteworthy that the short-circuiting period is characterized with a relatively higher rate of electrode melting due to higher current in comparison to the rate of wire feed. In contrast, the arcing period is characterized with a relatively reduced rate of electrode melting in comparison to the 
wire feed rate resulting in stubbing of the electrode in the melt pool and short-circuiting with the formation of a liquid bridge between the electrode and the melt pool ${ }^{8)}$. As shown in Fig. 2, the short-circuiting period begins with a drop down to a very low voltage and small current (image 1) that rapidly rises to a high peak causing substantial resistive heating and the growth of the liquid bridge (image 2) followed by its necking (image 3) and, next, shearing of the bridge and the re-ignition of a violent arc (image 4) due to high arcing voltage with the remaining high current at the same time. The arcing period is thus initiated and continues with the fall of the current and also of voltage to a lesser extent (images 5 to 7) till the molten electrode tip is about to contact the melt pool (image 8 ) to begin the next short-circuiting period. The increase in current in the short-circuiting period is nearly from $46( \pm 2)$ A to $270( \pm 10)$ A] while the short-circuiting voltage remains significantly low. The high short-circuiting current (corresponding to images 3) aids to high resistive heating of the liquid bridge as well as pinching of the liquid bridge near to electrode tip due to electro-magnetic force. However, the presence of the peak current at the time of re-ignition of the arc immediately after the pinching (shearing) of the liquid bridge also leads to a very high power arc that remains as an artefact of the conventional SCAW process. The time-averaged current and voltage are estimated $104( \pm 5) \mathrm{A}$ and 20 $( \pm 2) \mathrm{V}$, respectively over the complete short-circuiting and arcing period corresponding to a wire feed rate of $2.5 \mathrm{~m} / \mathrm{min}$.

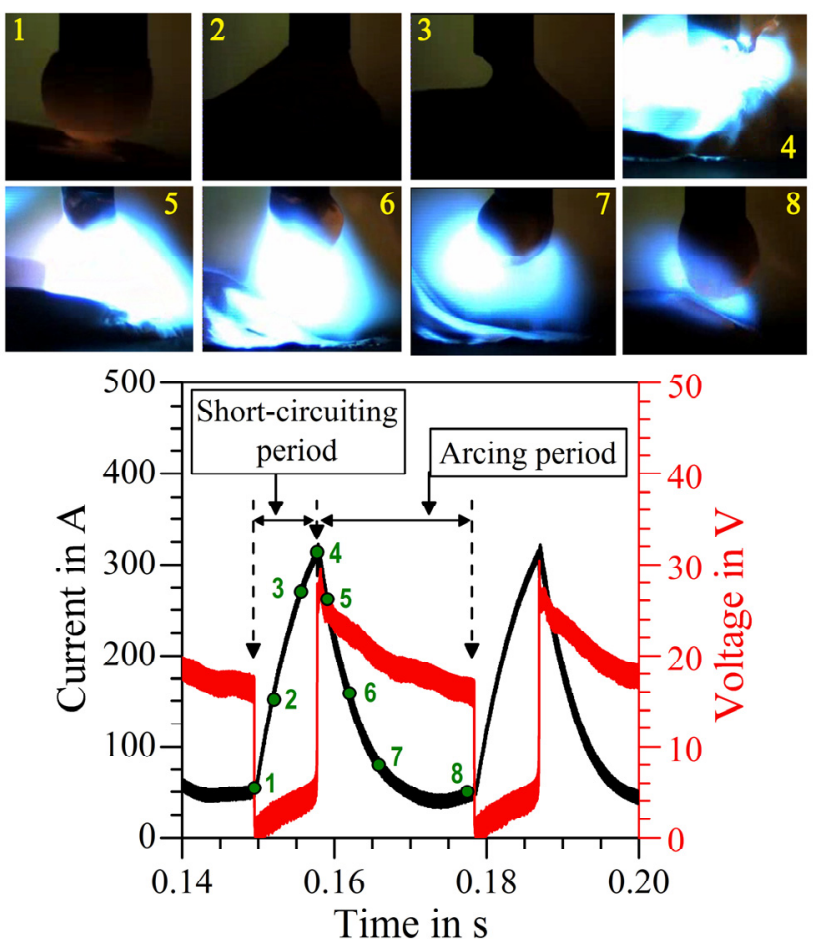

Fig. 2 Real-time current and voltage waveforms, and corresponding stages of materials transfer in conventional SCAW process at wire feed rate of $2.5 \mathrm{~m} / \mathrm{min}$. and welding speed of $15 \mathrm{~mm} / \mathrm{s}$.
Figure 3 depicts the measured current and voltage transients, and the stages of material transfer in the recently developed, advanced low energy input SCAW process at a wire feed rate of $2.5 \mathrm{~m} / \mathrm{min}$ and welding speed of $15 \mathrm{~mm} / \mathrm{s}$. Only one current and voltage cycle are shown in this case for a better clarity. It can be noted that the short-circuiting phase starts with a drop down to very low voltage and current (image 1). The current rapidly rises in a two-ramp function to a peak that is substantially smaller than the similar peak in the conventional SCAW process (Fig. 2). As the short-circuiting current rises in the low energy input SCAW process, the liquid bridge is heated due to resistive heating and begins to form a neck because of pinching force (images 2 and 3 ). In particular, a glowing thread of liquid bridge that is about to get sheared and deposited in the weld pool is worth noting (image 3). Further, the current is forced to drop down before the arc re-ignites with a rapid shooting up of the voltage to a peak for a very short duration. In this period, the current in reduced to a relatively smaller magnitude of about 50 A for a specific duration and thus, the re-ignition of the arc happens at a substantial low power (image 4) in contrast to a very high power arc re-ignition in the conventional SCAW process. As the arcing period proceeds, both current and voltage are increased first and reduced again in a controlled manner to form and maintain a molten drop of constant volume at the electrode tip (images 5, 6, 7 and 8). That the size of the molten drop at the electrode tip remains substantially small and controlled till it touches the melt pool is apparent (images 1 and 2 in Fig. 3 in contrast to images 1 and 2 in Fig. 2). Thus, the overall rate of heat input in the low energy input SCAW process remains significantly smaller in comparison to both the GMAW-P and the conventional SCAW processes at the same wire feed rate. A comparison of Figs 1 to 3 clearly indicates that the nature of both the current and voltage transients in the advanced low energy input SCAW process nearly mimics an engineered combination of the similar phenomena occurred in the GMAW-P and the conventional SCAW processes with the magnitudes of both current and voltage peaks remaining substantially smaller in the low energy input SCAW process. A combined effect of controlled deposition of electrode material in melt pool as in GMAW-P and the bridging transfer at significantly reduced rate of heat input as envisaged in the conventional SCAW process is thus achieved in the low energy input SCAW process.

Figure 4 depicts a comparison of the measured values of time-averaged values of current, voltage and power in GMAW-P, conventional SCAW and in the low energy input SCAW processes for a given wire feed rate of $2.5 \mathrm{~m} / \mathrm{min}$ and welding speed of $15 \mathrm{~mm} / \mathrm{s}$. The time-averaged currents and voltages are estimated over a few representative cycles and noted as $95 \mathrm{~A}$ and 19.5 $\mathrm{V}$ in GMAW-P, $118.15 \mathrm{~A}$ and $14.95 \mathrm{~V}$ in conventional SCAW and, 112.48 A and 15.25 V in the low energy input SCAW 
processes. The corresponding time-averaged powers are noted as $2.42,1.90$ and $1.65 \mathrm{~kW}$ for the GMAW-P, conventional SCAW and low energy input SCAW processes, respectively. It is thus noteworthy that the time-averaged rate of heat input in the low energy input SCAW process is significantly lower in comparison to the same in GMAW-P and fairly smaller with respect to the conventional SCAW processes for a given wire feed rate and welding speed.
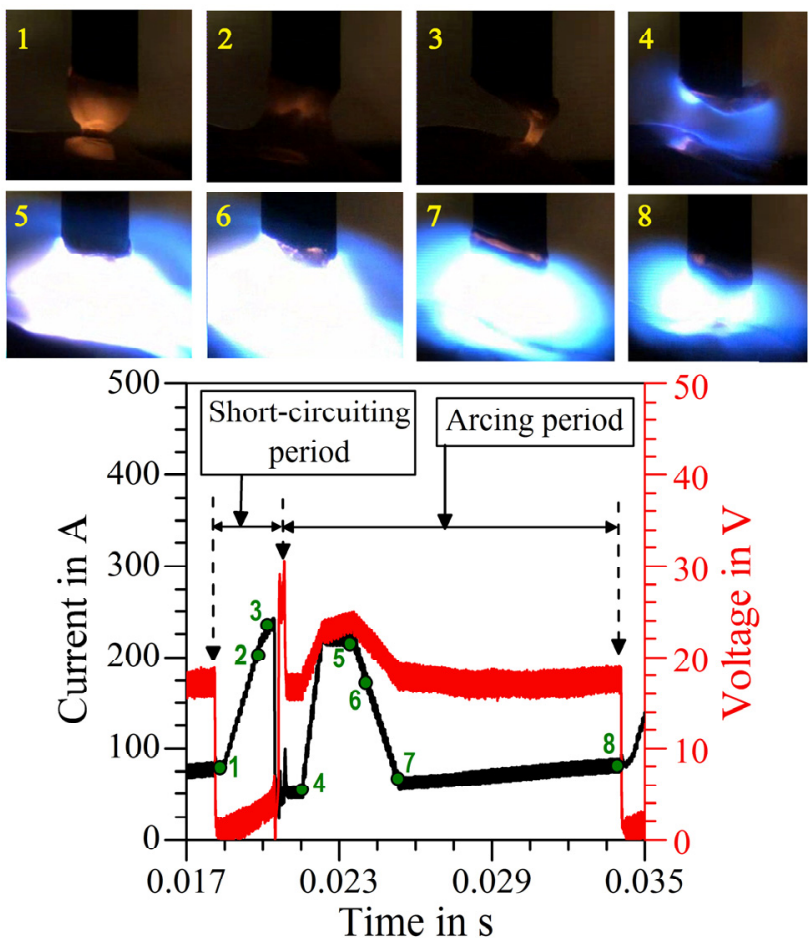

Fig. 3 Real-time current and voltage transients and corresponding stages of material transfer in the low energy input short-circuiting GMAW process at a wire feed rate of $2.5 \mathrm{~m} / \mathrm{min}$. and welding speed of $15 \mathrm{~mm} / \mathrm{s}$.

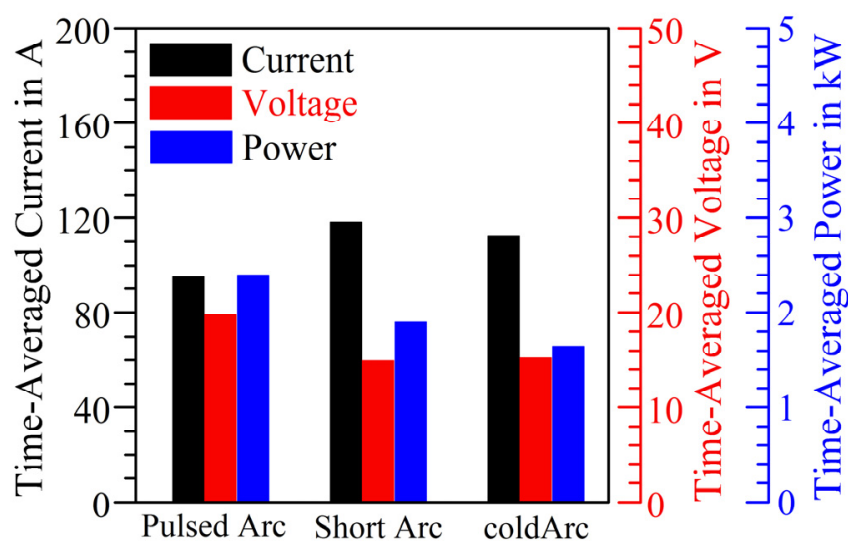

Fig. 4 Time-averaged values of current, voltage and power in pulsed arc (GMAW-P), short arc (conventional SCAW) and the recently developed low energy input SCAW processes for a wire reed rate of $2.5 \mathrm{~m} / \mathrm{min}$. and welding speed of $15 \mathrm{~mm} / \mathrm{s}$.

The reduced rate of heat input in the low energy input SCAW process further allows a remarkable decrease in welding-induced angular distortion of the fabricated joints, which is often a major challenge in joining of thin sheets due to the lesser stiffness of the weld joint assembly. A comparative assessment of the welding induced angular distortion at three different wire feed rates $(2.3$, 3.3 and $4.2 \mathrm{~m} / \mathrm{min}$ ) in GMAW-P and the low energy input SCAW processes is presented in Figure 5. The angular distortion is measured at three longitudinal points along the weld seam. Figure 5 shows that at a low wire feed rate of $2.3 \mathrm{~m} / \mathrm{min}$, the angular distortion is concave in nature in both GMAW-P and low energy input SCAW processes with the magnitude of the concavity significantly smaller in the latter case. With the increase in the wire feed rate to $3.3 \mathrm{~m} / \mathrm{min}$, the rate of heat input increases resulting in enhanced distortion in both the processes. As the wire feed rate is increased further to $4.2 \mathrm{~m} / \mathrm{min}$, the angular distortion remains concave and is enhanced further in GMAW-P process. In contrast, the angular distortion reduces significantly and becomes slightly convex in nature in the low energy input SCAW process.

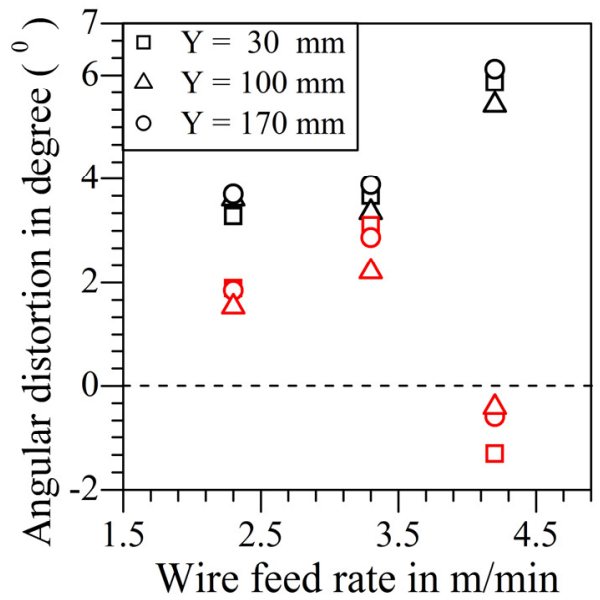

Fig. 5 Angular distortion in GMAW-P (black colored symbols) and low energy input SCAW (red colored symbols) processes at three wire feed rates $(2.3,3.3$ and $4.2 \mathrm{~m} / \mathrm{min})$ and constant welding speed of $15 \mathrm{~mm} / \mathrm{s}$. "Y" refers to the longitudinal distance from the weld start position along a total weld seam length of $200 \mathrm{~mm}$.

The typical nature of welding induced distortion in GMAW-P and low energy input SCAW processes can possibly be realized from the corresponding weld bead profiles. Figure 6 presents the weld joint cross-sections in GMAW-P and the low energy input SCAW processes at two different wire feed rates. A comparison of Figs 6(a) and (c) and, of Figs 6(b) and (d) clearly show the weld joints in GMAW-P with a greater weld bead width to penetration ratio than the same obtained in the low energy input SCAW. Since the welding induced distortion is greatly influenced by the relative shrinkage through the weld fusion zone (from the top surface to the root), it is axiomatic that a greater weld bead width with respect to the penetration will lead to a higher concave distortion. The higher rate of average heat input in GMAW-P in 
comparison to the low energy input SCAW process at a given wire feed rate has resulted in greater weld width and enhanced concave distortion. It is further noticeable that a smaller wire feed rate of $2.3 \mathrm{~m} / \mathrm{min}$ has resulted in incomplete penetration in both the processes while a complete penetration is obtained in both cases at the wire feed rate of $4.2 \mathrm{~m} / \mathrm{min}$. The weld fusion zone at the highest wire feed rate of $4.2 \mathrm{~m} / \mathrm{min}$ has attained a near finger-shape profile in GMAW-P resulting in significantly high angular distortion. In contrast, the fusion zone profile in the low energy input SCAW process at a wire feed rate of $4.3 \mathrm{~m} / \mathrm{min}$ depicts a smaller weld width to penetration ratio than the same obtained at a wire feed rate of $2.3 \mathrm{~m} / \mathrm{min}$ resulting in significantly reduced angular distortion in the former case i.e. at higher wire feed rate. The slight convex nature of angular distortion at higher wire feed rate in the low energy input SCAW process might have resulted due to the counter shrinkage action of the greater reinforcement profile that can be considered as an artifact.
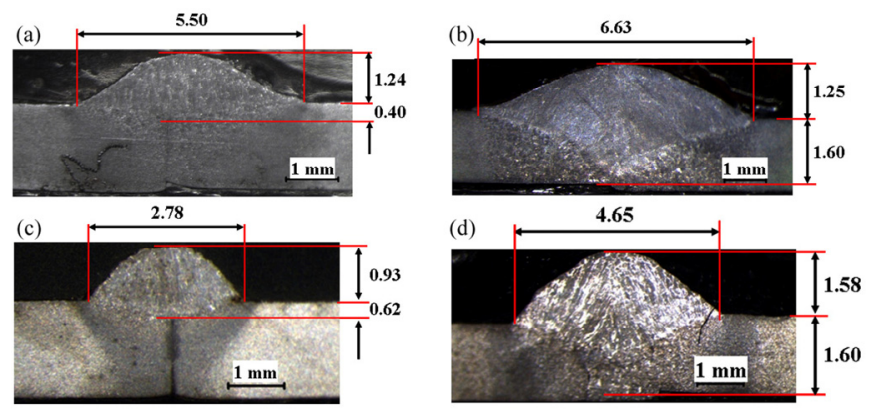

Fig. 6 Weld joint cross-sections in GMAW-P [(a), (b)] and in the low energy input SCAW [(c), (d)] processes. The wire feed rates for (a) and (c) is $2.3 \mathrm{~m} / \mathrm{min}$ and the same for (b) and (d) is $4.2 \mathrm{~m} / \mathrm{min}$. The welding speed is $15 \mathrm{~mm} / \mathrm{s}$ for all the four cases.

\section{Conclusions}

A quantitative assessment of real-time current and voltage transients and the corresponding nature of metal transfers in GMAW-P, conventional SCAW, and in a recently developed low energy input short-circuiting GMAW processes are presented. For a given wire feed rate, the low energy input short-circuiting GMAW significantly reduces the rate of energy input compared to both GMAW-P and the conventional SCAW processes. In particular, the low energy input SCAW process allows a significantly low power arc re-ignition and material detachment that eventually reduce spatter and angular distortion.

\section{Acknowledgements}

The authors are thankful to Professor Michael Rethmeier and Dr. Andreas Pittner of BAM, Germany for kindly supporting this work. The authors further wish to acknowledge the support from the DST, India and DAAD, Germany towards funding the exchange visits of the scholars within the framework of an Indo-German collaborative research project.

\section{Reference}

1) R.S. Parmar: Welding Engineering and Technology, Khanna publications (2007), New Delhi.

2) R.W. Messler: Principles of Welding, John Wiley \& Sons (2008), Singapore.

3) T.T. Allen, R.W. Richardson, D.P. Tagliabue and G.P. Maul: Statistical process design for robotic GMA welding of sheet metal, Weld. J., (2002), 69s-77s.

4) P.K. Ghosh, V.K. Goyal, H.K. Dhiman and M. Kumar: Thermal and metal transfer behaviors in pulsed current GMA weld deposition of Al-Mg alloy, Sci. Technol. Weld. Join., 11-2, (2006), 232-242.

5) T. Tanju and K. Turhan: Weldability of AISI 430/AISI 1030 steel couples via the synergic controlled pulsed and manual gas metal arc welding techniques, Materials and Manufacturing Processes, 26-7, (2011), 926-932.

6) C.G. Pickin and K. Young: Evaluation of cold metal transfer (CMT) process for welding aluminum alloys, Sci. Technol. Weld. Join., 11-5, (2006), 583-585.

7) T. Era, A. Ide, T. Uezono, T. Ueyama and Y. Hirata: Controlled bridge transfer (CBT) gas metal arc process for steel sheets joining, Sci. Technol. Weld. Join., 14-6, (2009), 493-499.

8) M. Hermans: A study of short circuiting arc welding, $\mathrm{PhD}$ Theis, Delft University Press (1997), The Netherlands.

9) S.F. Goecke: Reduced energy laser process for heat sensitive materials, DVS-Berichte, 237 (2005), 44-48.

10) M. Hübner, S-F. Goecke, H Schuster and A Müller: Neue Schweißverfahren im Karosseriebau als kostengünstige Alternative zum Laserstrahllöten, DVS-Congress, September 26 - 28, 2010, Nürnberg, DVS-Berichte, Band 267.

11) S-F Goecke: Self optimizing control and material transfer in the controlled short-arc process coldArc $\AA$, IIW-Doc XII-1989-09. Commission XII, IIW Annual Assembly, International Institute of Welding, Singapore, July 13-15, 2009.

12) S-F. Goecke: Der EWM-coldArc - Energiereduzierter Kurzlichtbogen. Große Schweißtechnische Tagung - GST 2006, (Konferenz-Einzelbericht), Aachen, September 20 - 22, 2006.

13) P. Praveen, M.J. Kang, P.K.D.V. Yarlagadda: Characterization of dynamic behavior of short circuit in pulse gas metal arc welding of aluminum, Journal of Achievements in Materials and Manufacturing Engineering, 14 -1, (2006) 75-82.

14) M.S. Weglowski, Y. Huang, Y. M. Zhang: Relation between wire feed speed and metal transfer in GMAW, Journal of Achievements in Materials and Manufacturing Engineering, 29-2, (2008), 191-194. 